\title{
Justice and the human alarm system: The impact of exclamation points and flashing lights on the justice judgment process is
}

\author{
Kees van den Bos ${ }^{\text {a,* }}$, Jaap Ham ${ }^{\text {a }}$, E. Allan Lind ${ }^{\text {b }}$, Marieke Simonis ${ }^{\text {a }}$, \\ Wiljo J. van Essen ${ }^{a}$, Mark Rijpkema ${ }^{\mathrm{c}}$ \\ a Department of Social and Organizational Psychology, Utrecht University, P.O. Box 80140, 3508 TC Utrecht, The Netherlands \\ ${ }^{\mathrm{b}}$ Fuqua School of Business, Duke University, The Netherlands \\ ${ }^{\mathrm{c}}$ F. C. Donders Centre for Cognitive Neuroimaging, Nijmegen University, The Netherlands
}

Received 24 August 2006; revised 22 January 2007

Available online 12 March 2007

\begin{abstract}
Extending theory within the justice domain and work on the human alarm system, the current paper argues that the process by which justice judgments are formed may be influenced reliably by the activation of psychological systems that people use to detect and handle alarming situations. Building on this analysis, it is further proposed that if this line of reasoning is true then presenting alarm-related stimuli, such as exclamation points and flashing lights, to people should lead to more extreme judgments about subsequent justice-related events than not presenting these alarming stimuli. Findings collected using different experimental paradigms provide evidence supporting these predictions both inside and outside the psychology lab. Implications for the social psychology of justice and the human alarm system literature are discussed.
\end{abstract}

(C) 2007 Elsevier Inc. All rights reserved.

Keywords: Justice; Fairness; Procedures; Outcomes; Human alarm system

A central finding in social psychology is the discovery that fair and unfair events have profound influence on people's justice judgments and that these judgments in turn often have important effects on other beliefs, attitudes, and behaviors (for overviews, see, e.g., Brockner \& Wiesenfeld, 1996; Folger \& Cropanzano, 1998; Lind \& Tyler, 1988; Tyler \& Lind, 1992). People distinguish readily between decisionmaking procedures according to the justice of these procedures. For example, when the procedure used to make a

\footnotetext{
The research reported in this paper was supported by a VICI innovational research grant from The Netherlands Organization for Scientific Research (NWO, 453.03.603) awarded to Kees van den Bos. We thank Henk Aarts, Rob Folger, Johan Karremans, Marjolein Maas, Dirk Steiner, Wolfgang Stroebe, Lorenz van Doornen, Frans Verstraten, Remco Wijn, and Arnaud Wisman for their suggestions during this research project and their comments on previous versions of this paper; and Marjolein Maas and Marijn Poortvliet for their assistance with collecting the data of Experiments 1 and 2.

* Corresponding author.

E-mail address: k.vandenbos@uu.nl (K. van den Bos).
}

decision entails the use of all relevant information vs. only some information, people evaluate the more accurate procedure as more just than the inaccurate procedure (see, e.g., Barrett-Howard \& Tyler, 1986; Van den Bos, Vermunt, \& Wilke, 1997; see also Leventhal, 1980). Similarly, when people are or are not allowed an opportunity to voice their opinion about decisions to be made, they generally judge the voice procedure as more just than the no-voice procedure (e.g., Folger, Rosenfield, Grove, \& Corkran, 1979; Lind, Kanfer, \& Earley, 1990; Van den Bos, Lind, Vermunt, \& Wilke, 1997). Comparable justice judgment effects have been found with respect to the allocation of outcomes: some of the classic studies in social psychology indicate that when people receive outcomes that are equal to the outcomes that comparable others have received they judge their outcome to be more just than when their outcome is worse than the others' outcome (see, e.g., Adams, 1965; Blau, 1964; Thibaut \& Kelley, 1959).

These findings show that people differentiate readily between fair and unfair procedures and outcomes. Other 
studies have shown that justice judgments have substantial effects on other beliefs and attitudes (Folger \& Cropanzano, 1998) and on behavior, especially cooperative behavior and compliance with authorities and organizations (Lind \& Tyler, 1988; Tyler \& Lind, 1992). For example, judging a particular outcome or treatment to be just appears to be among the prime antecedents of positive social actions like obeying laws (Tyler, 2006), accepting the decisions of group authorities (Tyler \& Lind, 1992), and behaving in ways that go "above and beyond" the requirements of one's job (Moorman \& Byrne, 2005). Judging procedural treatment or a division of outcomes to be unjust appears to be a strong antecedent of such actions as theft (Greenberg, 1993), violent aggression (Folger \& Skarlicki, 1998), and the initiation of lawsuits (Lind, Greenberg, Scott, \& Welchans, 2000). Indeed, work in various scientific disciplines (ranging from ethology to economics; see, e.g., De Waal, 1996; Kahneman, Knetsch, \& Thaler, 1986; Tyler, 2006) has shown that social justice represents a core issue in society, politics, organizations, and intimate relationships. As a result, justice considerations arise in almost every social situation in which people interact with each other (Folger, 1984). So, one can correctly assert that the study of how justice judgments are formed should occupy a prominent place in social psychological research. In this paper we focus on this issue.

More specifically, we will study here the social-cognitive dynamics of how justice judgments are formed. Although the first justice work in social psychology (Adams, 1965) merged concepts that we would now consider social cognition with concerns that arise in interpersonal relationships, much of the next three decades of social justice research was absorbed in documenting the importance of justice judgments and in analyzing the social psychology of justice largely from motivational perspectives (De Cremer \& Tyler, 2005; Tyler \& Lind, 1992). During those years, relatively less attention was given to the social-cognitive dynamics involved in generating social justice judgments (there were, however, some notable exceptions; see, e.g., Hafer, 2000; Steiner, Guirard, \& Baccino, 1999). Recently, a new wave of social justice research has begun investigating how justice judgments are formed (e.g., Brockner \& Wiesenfeld, 1996; Van den Bos, 2001; Van Prooijen, Karremans, \& Van Beest, 2006), and the findings of this research have helped social psychology to generate new models of social justice (e.g., Brockner \& Wiesenfeld, 1996; Van den Bos \& Lind, 2002) or to refine insights into existing justice theories and other important social psychological frameworks (e.g., Van den Bos, Poortvliet, Maas, Miedema, \& Van den Ham, 2005; Van den Bos \& Van Prooijen, 2001). In the studies reported in the current paper we continue this new line of social justice research by testing a possible connection between a newly established social justice phenomenon (the augmentation of justice effects in the presence of personal uncertainty or other self-threatening conditions) and some potentially related phenomena in social cognition and social neuroscience showing the possi- ble existence of a "human alarm system" (Eisenberger \& Lieberman, 2004; Eisenberger, Lieberman, \& Williams, 2003; Lieberman \& Eisenberger, 2004; Murray, Holmes, \& Collins, 2005; see also Carter et al., 2000; Klein, 1996; Liddell et al., 2005; Tillfors, 2004). Integrating these two lines of research, we provide impetus to the development of a theoretically new perspective on how people form justice judgments, the alarm-system model of the justice judgment process.

\section{An alarm-system model of justice judgments}

Our previous work emphasized the important role that personal uncertainty (see, e.g., Van den Bos, 2001; Van den Bos \& Lind, 2002) or other self-threatening conditions (see, e.g., Miedema, Van den Bos, \& Vermunt, 2006) play in the process of how people form justice judgments. Most uncertainty management models (e.g., Hogg, 2004; McGregor, 2004; Van den Bos \& Lind, 2002) assume that people have a fundamental need to feel certain about their world and their place within it, that uncertainty can be threatening, and that people generally feel a need either to eliminate uncertainty or to find some way to make it tolerable and cognitively manageable. Therefore, many uncertainty management theories propose that people want to protect themselves from being in or thinking of situations in which they were uncertain about themselves. One way in which people can do this is by adhering to their cultural norms and values (e.g., Van den Bos et al., 2005). Experiences that are supportive of people's cultural worldviews lead them to be less uncertain about themselves or to be better able to better tolerate the uncertainty (e.g., Van den Bos, Heuven, Burger, \& Fernández Van Veldhuizen, 2006). As a result, uncertainty management theories hypothesize that people who are uncertain about themselves or who have been reminded about their personal uncertainties will react very positively toward worldview-supportive experiences (such as experiences of fair treatment; e.g., Van den Bos, 2001). In contrast, experiences that threaten or impinge on people's worldviews do not help at all to in coping with personal uncertainties, and hence people will respond very negatively toward these worldview-threatening experiences (such as experiences of unfair events; e.g., Van den Bos et al., 2005).

Several research studies indeed have shown that reminding people of their personal uncertainties lead to more intensified judgments of fair and unfair events so that people make more extreme judgments about accurate or inaccurate procedures, voice or no-voice procedures, and good or bad outcomes when uncertainty is salient (e.g., Van den Bos, 2001; Van den Bos et al., 2005; see also De Cremer \& Sedikides, 2005). Furthermore, Miedema et al. (2006) revealed that when people feel they have been judged negatively by important others, this will lead to interaction effects with fairness manipulations such that people will show more extreme judgments of procedural and outcome justice when they have been confronted with these kinds of 
self-threats than when they have not been faced with these self-threats.

Thus, it is now well established in the justice literature that personal uncertainty (Van den Bos, 2001; Van den Bos \& Lind, 2002; Van den Bos et al., 2005) and other self-threatening conditions (Miedema et al., 2006) lead to more extreme judgments about procedural and outcome justice. Interestingly, in the literatures on close relationships and social neuroscience, personal uncertainty and self-threats recently have been suggested to lead to the activation of the "human alarm system," a psychological system that people use to detect and handle alarming situations and that prompts people to process more alertly what is going on in the situations they find themselves in. For example, Murray et al. (2005) recently suggested that personal uncertainty (Murray, Rose, Bellavia, Holmes, \& Garrett Kusche, 2002; see also Hogg, 2005; McGregor, Zanna, Holmes, \& Spencer, 2001) and felt insecurity in close relationships (Murray, 2005; Murray, Holmes, \& Griffin, 2000; Murray, Holmes, MacDonald, \& Ellsworth, 1998) activate the human alarm system so that, among other things, people process more alertly what is happening in their relationships.

Related to this, Eisenberger et al. (2003) have argued that being ostracized or experiencing other self-threatening events activates parts of the human brain which Eisenberger et al. have labeled the human alarm system. Furthermore, Eisenberger and Lieberman (2004; Lieberman and Eisenberger, 2004) proposed that the alarm system is responsible for detecting cues that might be harmful to survival and, after activation, for recruiting attention and coping responses to minimize threat. For example, Eisenberger et al. (2003) have argued that experiencing social exclusion or other self-threatening events may be an experience of social pain. Like physical pain, the experience of social pain may trigger the human alarm system, hence "alerting us when we have sustained injury to our social connections" (Eisenberger et al., 2003, p. 292, emphasis added). The working of such an alarm system would be adaptive (see Eisenberger \& Lieberman, 2004) in that an activated alarm system would prompt the human organism to act and respond more quickly or otherwise alertly toward what is going on in the organism's environment.

What we are proposing here is that one way to triangulate the relationships between personal uncertainty and self-threats (Miedema et al., 2006; Van den Bos, 2001; Van den Bos et al., 2005), the human alarm system (Eisenberger \& Lieberman, 2004; Eisenberger et al., 2003; Murray et al., 2005), and social justice judgments is by conceptualizing an overlap between the alarm system and the justice judgment process. We think it is interesting to propose such an overlap because one of the hypotheses that could be derived from such a postulated overlap is that factors that people associate with alarming conditions should enhance the sensitivity of the alarm system and thus, given the postulated overlap, potentiate sensitivity to the justicerelated events people subsequently experience. So, just as
Eisenberger and Lieberman (2004) postulated that the brain bases of social pain are similar to those of physical pain and hypothesized that "factors that enhance the sensitivity to one type of pain should enhance the sensitivity of this alarm system and thus potentiate sensitivity to the other type of pain as well', (p. 297), we postulate here that presenting to people alarm-related symbols should activate the human alarm system and hence potentiate sensitivity to other types of processes associated with it as well, including enhanced sensitivity to the justice judgment process, thus making people to react more sensitively toward subsequently experienced fair or unfair events, such as good or bad procedures and outcomes.

More specifically, from the literature reviewed here at least two things can be concluded: (1) personal uncertainty and other self-threatening conditions activate the human alarm system (Eisenberger et al., 2003; Murray et al., 2005); and (2) personal uncertainty and self-threatening conditions lead to more extreme judgments about procedural and outcome justice (Miedema et al., 2006; Van den Bos, 2001; Van den Bos et al., 2005). Thus, it is known that the same conditions that may activate the human alarm system may also lead to more extreme justice judgments. Building on this observation, this suggests that activating the human alarm system directly, for example by presenting alarm-related stimuli to people, should lead to more extreme judgments about procedural and outcome justice. An intriguing hypothesis that therefore follows from the line of reasoning presented here is that the presentation of cues that are closely or even subtly related to alarming conditions may lead people to form more extreme judgments about subsequently presented procedures and outcomes. The current paper tests whether reliable evidence for this hypothesis can be found.

\section{The current research}

To our knowledge, the alarm-system perspective has not been integrated with the justice literature before, so the union of the two lines of work may be a strength of the current paper and may give new insights into the process by which justice judgments are formed. Furthermore, we think there are at least three other reasons that obtaining evidence for this line of reasoning may make a new contribution to the literature.

First, besides the convergence of phenomena suggested by similarities between the uncertainty and self-threat findings reported in the alarm-system (Eisenberger et al., 2003; Murray et al., 2005) and justice literatures (Miedema et al., 2006; Van den Bos, 2001; Van den Bos et al., 2005), we think there are other good reasons that an alarm-system view of the justice judgment process may need to be incorporated into theories of the social psychology of justice. After all, adopting an alarm-system perspective suggests that an important function of social justice may be that justice is one of the signs to which Murray et al. (2005) and Eisenberger and Lieberman (2004; Eisenberger et al., 
2003) were referring when proposing that people with an activated alarm system would look for information what is happening in the situation in which they find themselves. In fact, in correspondence with the relational work by Murray et al. $(1998,2000,2002,2005)$ and the social exclusion work by Eisenberger et al. (2003), social justice has been explicitly linked to indications of good relational treatment (Tyler \& Lind, 1992). Fair procedures and outcomes are thought to be signals of whether one is included as opposed to excluded from important relationships (Lind, 2001; Leung, Tong, \& Ho, 2004; Van den Bos, Lind, $\&$ Wilke, 2001). The relational quality of fair treatment and the inclusion message conveyed by fair events suggest that, after the alarm system has been activated, experiencing fair treatment and other fair events may well signal that threats are less severe than was assumed during the activation of the alarm system.

Second, if the line of reasoning that we have developed here is true then it should be the case that presenting social cues that are even only subtly related to alarming conditions will lead people to form more extreme procedural and outcome justice judgments. In Experiments 1-3 of this paper, we will test the implications of this line of reasoning by presenting exclamation points (vs. blank screens or scrambled exclamation points) to our participants. We argue that people have learned to associate exclamation points with signals to be alert that something is or will be going on. For example, at www.wikepedia.com, an encyclopedia on the internet, it is stated that exclamation points are often used to emphasize a warning and that warning signs are often an exclamation point enclosed within a triangle. Furthermore, on these warning signs, exclamation points are often used to draw attention to a warning of danger, hazards, and the unexpected. These signs are common in hazardous environments or on potentially dangerous equipment. Granted, exclamation points may not always indicate alarm (as in the case of ending a sentence telling someone that something she did was simply great). But when presented alone, the exclamation point usually is a warning sign, quite often seen in Europe - where our research was conducted - and elsewhere as a road sign and a warning to be careful. We therefore reason that if our line of reasoning about connections between a human alarm system and the justice judgment process is true then this implies that the presentation of exclamation points, being symbols that are subtly related to alarming conditions, should lead participants to form more extreme justice judgments in a subsequent, unrelated task. Specifically, we test whether exposure to exclamation points later produce more extreme justice judgments about accurate or inaccurate procedures (Experiment 1), good or bad outcomes (Experiment 2), and voice or no-voice procedures (Experiment 3).

Third, if our line of reasoning has merit then we should be able to find evidence for it outside the psychological laboratory. In Experiment 4, therefore, we test our line of reasoning in a real-world setting by interviewing people about good and bad outcome distributions in a situational context where a flashing warning light of the sort used on emergency vehicles or to warn of road hazards had (vs. had not) been switched on. Following our research hypothesis, we examine whether people will show more extreme outcome justice judgments when the flashing light was switched on. With all our experiments we try to achieve an important aim of this paper, namely to show that the justice judgment process may well be affected by alarming stimuli; stimuli that, we think, most justice researchers would not have thought to have an effect on people's justice judgments, yet that logically can be derived from the alarm-system view of the justice judgment process presented here.

\section{Experiment 1}

In Experiments 1 and 2, participants in our experimental conditions viewed an exclamation point prior to, and unrelated to, evaluating the justice of an accurate or inaccurate procedure (Experiment 1; cf. Barrett-Howard \& Tyler, 1986; Leventhal, 1980; Van den Bos et al., 1997) and a good or bad outcome (Experiment 2; cf. Adams, 1965; Blau, 1964; Thibaut \& Kelley, 1959). Following the line of reasoning described above, we predicted that having participants look at these alarmrelated symbols would lead to their justice judgments being more strongly affected by the information conveyed by our procedure and outcome manipulations, compared to when participants did not look at exclamation points. This prediction constituted our main hypothesis of Experiments 1 and 2.

Furthermore, if exclamation points are indeed symbols that signal to people to be alert, as we are proposing here, then this should be evident in cognitive process measures. Evidence in cognitive psychology suggests that increased alertness is indicated by more rapid responding to subsequent events (e.g., Callejas, Lupianez, \& Tudela, 2004; see also Posner \& Petersen, 1990). This suggests that support for our line of reasoning should be indicated by faster responses among participants in our exclamation point conditions when judging the justice of the events they subsequently experience, compared to participants who did not look at exclamation points. To check whether watching exclamation points indeed has these effects on participants' response latencies, the time participants needed to answer the justice judgments of Experiments 1 and 2 was measured.

We hasten to note that although we argue that the modal consequence of enhanced activity of the alarm system may be faster responding to subsequently experienced procedures and outcomes, it may be likely that there is a range of consequences of enhanced activity of the alarm system. In humans, for example, an alarm signal may set in motion contemplation or introspection, not for the purpose of an immediate response but simply to understand the nature of one's social environment or to consider how the event 
producing the alarm reflects on one's identity and selfworth (Lieberman \& Eisenberger, 2004). Thus, although we propose that activating the human alarm system will lead to more alert information processing as indicated in participants forming their justice judgments more rapidly, it could also be predicted that more alert processing could lead to a more cautious analysis of the justice outcome and thus to slower response latencies. While this sometimes may be the case, we also think that it is reasonable to propose that the modal response of an alerted organism may be faster responding to events encountered by the organism (see also Lieberman \& Eisenberger, 2004). Most alarming situations do not allow for contemplation and introspection, but rather require that people respond rather quickly to what is going on. The response latencies data we collected in Experiments 1-3 were assessed to find out whether this line of reasoning has merit.

\section{Method}

\section{Participants and design}

One hundred and twenty-four students $(85 \text { women })^{1}$ at Utrecht University participated in the experiment and were paid for their participation. Participants were randomly assigned to one of the conditions of the 2 (characters: exclamation point vs. none) $\times 2$ (procedure: accurate vs. inaccurate) factorial design. Thirty-one participants took part in each of the four conditions.

\section{Experimental procedure}

Students at Utrecht University were invited to the laboratory to participate in a study on how people perform tasks. On arrival at the laboratory, participants were led to separate cubicles, each of which contained a computer with a monitor and a keyboard. The computers were used to present the stimulus information and to measure the dependent variables and the manipulation checks. Participants took part in our experiment after participating in other, unrelated experiments. The experiments lasted a total of $30 \mathrm{~min}$, and participants were paid 4 Euros for their participation (1 Euro equaled approximately $\$ 1.25$ U.S. at the time the studies in this paper were conducted).

The experiment was presented to the participants as two separate studies. In the first study, all the participants were told that recent research had suggested that looking at their computer screens for $1 \mathrm{~min}$ would help the researchers of the current study in their research efforts. Participants were therefore asked to look at their computer screens for $1 \mathrm{~min}$. The characters manipulation was then induced: in the exclamation point condition, an exclamation point of $30 \times 5 \mathrm{~mm}$ (which is $1.18 \times 0.20$ in.) was presented for

\footnotetext{
${ }^{1}$ In the experiments presented here, controlling for gender did not alter the interpretation of the findings reported nor did the other demographic variables of Experiment 4 affect the results. Hence, these variables were dropped from the analyses.
}

1 min at the center of participants' screens. In the no characters condition, no characters were presented on participants' computer screens.

After this, all participants completed the Positive and Negative Affect Schedule (PANAS; Watson, Clark, \& Tellegen, 1988), on which they reported on 20 items how they felt at the moment. Building on earlier justice studies (e.g., Van den Bos, 2001; Van den Bos \& Miedema, 2000), the PANAS served as a filler task and to determine whether the characters manipulation engendered effects on positive and negative affect. The PANAS is the most widely used affect scale in social psychology and consists of two 10-item subsets (Watson et al., 1988), one measuring positive affect (PA) and one measuring negative affect (NA). Following recommendations by Watson et al. (1988) and following previous studies (e.g., Van den Bos, 2001; Van den Bos \& Miedema, $2000)$ both subsets were averaged to form reliable scales $(\alpha$ 's $=.89$ and .80 , respectively).

After the first study had ended, the second study began. In this study, participants were asked to imagine the following situation:

You are someone who wants a job. You have applied for a vacant position in an organization, MicroMac Inc., and you want this position very much. MicroMac informs you that they are interested in you and they invite you to participate in the selection process that, as a standard procedure, all screened applicants at MicroMac have to complete. The selection process consists of nine parts: an intelligence test, a personality test, a test assessing mathematics skills, a test assessing understanding of technical matters, a test assessing calculation skills, a test assessing language skills, a questionnaire assessing demographic data, a test assessing achievement motivation, and an interview with a personnel officer at MicroMac. You go to MicroMac and participate in the selection process.

This was followed by the manipulation of procedure. Participants read the sentence (manipulated information in italics):

A week after you participated in the selection process you are informed that all 9 parts/ 1 of the 9 parts of the selection process were graded.

This manipulation, varying whether the procedure to make an outcome decision entails the use of all relevant information (accurate procedure) vs. only some information (inaccurate procedure), is one that is often used in the social justice literature (e.g., Van den Bos et al., 1997; see also Leventhal, 1980).

After this manipulation, the dependent variables were measured. All ratings were made on 7-point Likert-type scales. The main dependent variables in Experiment 1 were participants' judgments of procedural justice: participants were asked how just $(1=$ very unjust, $7=$ very just $)$, appro- 
priate $(1=$ very inappropriate, $7=$ very appropriate $)$, and justified $(1=$ very unjustified, $7=$ very justified $)$ they considered the way they were treated. Participants' answers to these three items were averaged to form a reliable scale of procedural justice judgments $(\alpha=.97)$. As mentioned earlier, as a check on the characters manipulation, the time that participants needed to answer the procedural justice judgments was measured by the computers. ${ }^{2}$ After this, participants were paid for their participation and were thoroughly debriefed. During the debriefing procedure, participants indicated that they did not perceive a direct relationship between the characters manipulation and their reactions to the application scenario. Participants were not suspicious about our manipulations and did not object to the experimental procedure used in the experiment.

\section{Results}

\section{Manipulation check}

A $2 \times 2$ analysis of variance (ANOVA) on the response latencies scale showed a main effect of the characters manipulation only, $F(1,118)=6.08, p<.02$. This indicated that participants in the exclamation point condition responded faster to the procedural justice questions $(M=3.12 \mathrm{~s}$, $S D=1.66 \mathrm{~s}$ ) than participants in the no characters condition ( $M=3.62 \mathrm{~s}, S D=1.46 \mathrm{~s})$. We will return to these findings in Experiments 2 and 3 and in the General discussion.

\section{PANAS}

The PANAS was administered following the characters manipulation, as a filler task and to determine whether there were effects of the characters manipulation on the positive and negative subsets. A $2 \times 2$ multivariate analysis of variance (MANOVA) on the positive and negative subsets of the PANAS yielded no effects at both the multivariate and univariate levels. This suggests that differences in affective states cannot explain the findings reported here. Overall means of the positive and negative subsets were $2.64(S D=0.77)$ and $1.34(S D=0.39)$, respectively. Furthermore, after applying the appropriate

\footnotetext{
${ }^{2}$ Distributions of response latencies generally are positively skewed (Kirk, 1995). Part of this may be caused by the fact that some participants accidentally were not paying attention to the items they were supposed to respond to. Therefore, following recommendations by Fazio (1990), the response latencies were first checked for extreme outliers. Two (out of 124) participants were indeed extreme outliers (see Fazio, 1990) as the response latencies of these 2 participants $(M \mathrm{~s}=10.49$ and 13.06) were three standard deviations above the overall mean $(M=3.51, S D=1.90)$. As suggested by Fazio (1990), the response latencies of these 2 participants were discarded. Logarithmic transformations were applied to the remaining response latencies. This transformation is suggested for variables that are positively skewed, such as response latencies (Kirk, 1995). Participants' transformed response latencies were averaged to form a reliable scale of their response latencies $(\alpha=.78)$. Analysis of variance was conducted on this scale of transformed response latencies. To make interpretation of the analysis of variance results more understandable, we will present the relevant means and standard deviations in seconds, and not in logarithmically transformed values.
}

Bonferroni adjustment (see Hays, 1981), a $2 \times 2$ MANOVA on all the 20 PANAS items did not yield any significant effects, suggesting that in Experiment 1 specific affective reactions were not influenced by our exclamation point manipulation.

\section{Dependent variables}

Participants' procedural justice judgments indicated a main effect of procedure, $F(1,120)=123.83, p<.001$, and the predicted interaction effect, $F(1,120)=5.89$, $p<.02$. The main effect of the characters manipulation was not significant. Fig. 1 shows these effects. As hypothesized, results showed that the simple main effect of the procedure manipulation was stronger in the exclamation point condition, $F(1,120)=91.87, p<.001, \eta^{2}=.43$, than in the no characters condition, $F(1,120)=37.85$, $p<.001, \eta^{2}=.24$. Thus, replicating earlier procedural justice studies (e.g., Van den Bos et al., 1997), these findings indicate that in the no characters condition, participants' justice judgments were more positive following the accurate procedure information $(M=4.60$, $S D=1.43)$ than following the inaccurate procedure information $(M=2.66, S D=1.17)$. Furthermore, as predicted in the current paper, in the exclamation point condition the difference between the accurate $(M=5.30$, $S D=1.30)$ and inaccurate $(M=2.27, S D=1.17)$ procedure conditions was even greater.

It can also be noted here that the characters manipulation yielded a significant simple main effect within the accurate procedure condition, $F(1,120)=4.88, p<.03$, and a statistically nonsignificant effect within the inaccurate procedure condition, $F(1,120)=1.50, p>.22$. We will come back to this finding in the General discussion.

\section{Discussion}

As hypothesized on the basis of our integration of the social justice literature (e.g., Miedema et al., 2006; Van den Bos, 2001; Van den Bos et al., 2005) with recent developments within the psychology of human alarm systems (e.g., Eisenberger et al., 2003; Murray et al., 2005), the findings of Experiment 1 show that watching exclamation

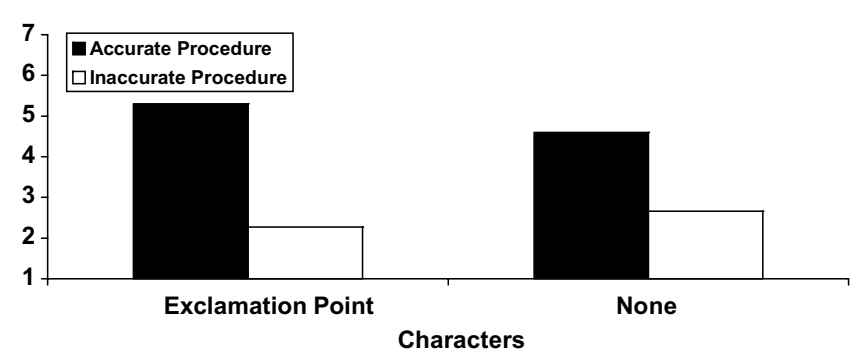

Fig. 1. Mean procedural justice judgments as a function of the characters and procedure manipulations of Experiment 1. Means are on 7-point scales, with higher values indicating higher levels of judgments of procedural justice. 
points indeed cause people's justice judgments to be more extreme when responding to variations in procedural accuracy. Furthermore, in accordance with evidence in cognitive psychology that increased alertness is indicated by more rapid responding to subsequent events (e.g., Callejas et al., 2004; Posner \& Petersen, 1990), our findings also showed that participants in the exclamation point condition took less time to construct their justice judgments. The findings reported in Experiment 1 are exciting, we think, partly because until the analysis of the justice judgment process put forward in the current paper, these effects would not have been predicted by social psychologists and other scientists studying social justice, yet they confidently could be predicted following the alarm-system view of the justice judgment process presented here. Before we draw any strong conclusions on the basis of these findings, however, it was important to conduct a second experiment.

\section{Experiment 2}

Participants in the experimental condition of Experiment 2 again viewed an exclamation point. To ensure an even better control condition than in Experiment 1, participants in the control condition of Experiment 2 viewed a scrambled exclamation point. That is, in the control condition of Experiment 2, the components that constitute an exclamation point (a line and a dot) were now rearranged such that they did not constitute an exclamation point any more. In this way, participants in both the experimental and the control conditions viewed the same characters (a line and a dot), but in the experimental condition the characters constituted an exclamation point whereas in the control condition they did not.

Because the psychology of justice entails judgments of outcome justice, as well as judgments of procedural justice (cf. Experiment 1), we varied that participants of Experiment 2 received either a good or a bad outcome such that participants received an outcome that was either equal to or that was worse than the outcome of a comparable other person (cf. Adams, 1965; Blau, 1964; Thibaut \& Kelley, 1959; see also Van den Bos, Wilke, Lind, \& Vermunt, 1998). Our main dependent variables were participants' justice outcome judgments, and again we checked the time participants needed to complete these judgments.

\section{Method}

\section{Participants and design}

Fifty-nine students (43 women) at Utrecht University participated in the experiment and were paid for their participation. Participants were randomly assigned to one of the conditions of the 2 (characters: exclamation point vs. scrambled exclamation point) $\times 2$ (outcome: good vs. bad) factorial design. Fourteen or 15 participants took part in each of the four conditions.

\section{Experimental procedure}

The experimental procedure was the same as in Experiment 1, except for the points mentioned below. Participants took part in the experiment before and after participating in other, unrelated experiments. The experiments lasted a total of $40 \mathrm{~min}$, and participants were paid 4 Euros for their participation.

The experiment was again presented to the participants as two separate studies. The first study was the same as in Experiment 1, except that in the control condition the characters (line and dot) that formed the exclamation point in the exclamation point condition were now rearranged such that they did not constitute an exclamation point any more. More specifically, in the exclamation point condition the following set of characters were presented for $1 \mathrm{~min}$ at the center of participants' screens:

whereas in the control condition the following set of characters were presented for 1 min:

After this, as in Experiment 1, all participants completed the PANAS, with both the positive and negative subsets again yielding reliable scales $(\alpha$ 's $=.88$ and .80 , respectively).

After the first study had ended, the second study started. In this study, participants were asked to imagine the following situation:

In the dorm where a friend of yours is living a room is vacant. You are applying for this room. You know that your friend's room is comparable to the room you are applying for and that she pays a monthly rent of 200 Euros for her room.

This was followed by the manipulation of outcome. Participants read the sentence (manipulated information in italics):

You go to the dorm and there you are told that you will have to pay a monthly rent of 200/300 Euros for your room.

The manipulation of the payment to be equal to vs. higher than that paid by a similarly situated other is a classic manipulation of outcome fairness (e.g., Adams, 1965).

The dependent variables were then measured. Building on Experiment 1, participants' judgments of outcome justice were assessed by asking participants how just $(1=$ very $\quad$ unjust, $\quad 7=$ very just $), \quad$ appropriate $(1=$ very inappropriate, $7=$ very appropriate $)$, and justified $(1=$ very unjustified, $7=$ very justified $)$ they considered the rent that they had to pay for their room. Participants' answers to these three items were averaged to form a reliable scale of their outcome justice judgments $(\alpha=.98)$. As check on the characters manipula- 
tion, the time that participants needed to answer the outcome justice judgments was measured by the computers. $^{3}$

After this, participants were paid for their participation and were thoroughly debriefed. During the debriefing procedure, participants indicated that they did not perceive a direct relationship between the characters manipulation and their reactions to the room scenario. Participants were not suspicious about our manipulations and did not object to the experimental procedure used in the experiment.

\section{Results}

\section{Manipulation check}

As in Experiment 1, a $2 \times 2$ ANOVA on the response latencies scale showed a main effect of the characters manipulation, $F(1,54)=12.87, p<.01$, revealing that participants in the exclamation point condition took significantly less time to respond to the outcome justice questions $(M=3.14 \mathrm{~s}, S D=1.67 \mathrm{~s})$ than participants in the control condition $(M=5.09 \mathrm{~s}, S D=2.72 \mathrm{~s})$.

\section{PANAS}

As in Experiment 1 , a $2 \times 2$ MANOVA on the positive and negative subsets of the PANAS yielded no effects at both the multivariate and univariate levels. This suggests that overall affective states cannot explain the findings reported here. Overall means of the positive and negative subsets were $2.39(S D=0.76)$ and 1.23 $(S D=0.32)$, respectively. A $2 \times 2$ MANOVA on all the 20 PANAS items showed that, after applying the appropriate Bonferroni adjustment (see Hays, 1981), a significant effect of the exclamation point manipulation on the item that assesses excitement was found, $F(1,55)=7.36, p<.01$. This effect indicated that participants felt more excited in the exclamation point condition $(M=1.87, S D=0.97)$ than in the scrambled exclamation point condition $(M=1.31, S D=0.54){ }^{4}$ We will discuss the implication of this finding in the General discussion.

\footnotetext{
${ }^{3}$ The response latencies of 1 participant $(M=17.86)$ were three standard deviations above the overall mean $(M=4.32, S D=3.00)$. Using the same statistical procedures as in Experiment 1, the response latencies of this participant were discarded, logarithmic transformations were applied to the remaining response latencies, and participants' transformed response latencies were averaged to form a reliable scale of their response latencies $(\alpha=.90)$.

${ }^{4}$ When we controlled for participants' excitement scores, participants' outcome justice judgments still yielded a significant interaction effect, $F(1,54)=5.75, p<.03$, showing that the effect of the outcome manipulation was stronger in the exclamation point condition, $F(1,54)=236.48$, $p<.001, \eta^{2}=.81$, than in the scrambled exclamation point condition, $F(1,54)=135.96, p<.001, \eta^{2}=.72$.
}

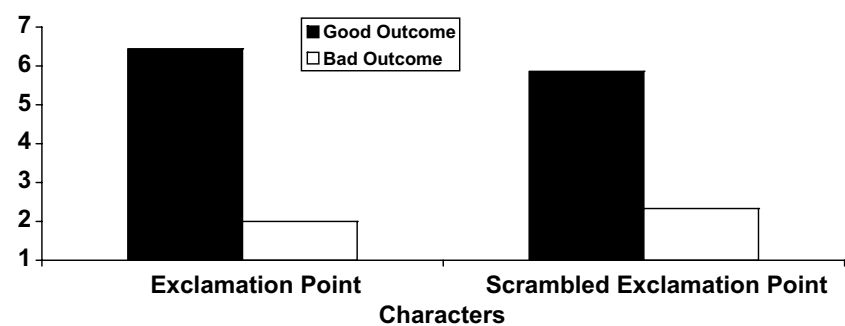

Fig. 2. Mean outcome justice judgments as a function of the characters and outcome manipulations of Experiment 2. Means are on 7-point scales, with higher values indicating higher levels of judgments of outcome justice.

\section{Dependent variables}

Participants' outcome justice judgments indicated a main effect of outcome, $F(1,55)=365.55, p<.001$, as well as the predicted interaction effect, $F(1,55)=4.88, p<.04$. The main effect of the characters manipulation was not significant. Fig. 2 graphs these effects. As hypothesized, results showed that the simple main effect of the outcome manipulation was stronger in the exclamation point condition, $F(1,55)=231.51, p<.001, \eta^{2}=.81$, than in the control condition, $F(1,55)=140.95, p<.001, \eta^{2}=.72$. Thus, as predicted, these findings indicate that in the scrambled exclamation point condition, participants' justice judgments were more positive following the good outcome $(M=5.86, S D=1.00)$ than following the bad outcome $(M=2.33, S D=0.98)$. Furthermore, in the exclamation point condition, the difference between the good $(M=6.44, S D=0.66)$ and bad $(M=2.00, S D=0.42)$ outcomes was even greater.

The characters manipulation yielded a significant simple main effect within the good outcome condition, $F(1,55)=5.99, p<.02$, and a statistically nonsignificant effect within the bad outcome condition, $F(1,55)=1.30$, $p>.25$. We will come back to this finding in the General discussion.

\section{Discussion}

In line with what was predicted on the basis of the alarm-system view of the justice judgment process developed here, the findings of Experiments 1 and 2 reveal that looking at exclamation points lead people to show more extreme justice judgments in response to variations in procedural (Experiment 1) and outcome information (Experiment 2). Also, as predicted on the basis of cognitive psychological research (see, e.g., Callejas et al., 2004; Posner \& Petersen, 1990), participants in the exclamation point conditions of both experiments needed less time to give their justice judgments. These findings suggest that watching exclamation points does indeed lead to a more alert judgment process (Callejas et al., 2004; Posner \& Petersen, 1990) and more extreme justice judgments, not only compared to people who look at blank screens (Experiment 1), but also compared to those who watch scrambled excla- 
mation points (Experiment 2). However, before further conclusions were drawn, a third experiment was conducted.

\section{Experiment 3}

Participants in Experiments 1 and 2 read and responded to justice scenarios. One might wonder whether similar results would be obtained when participants were exposed to a situation in which they directly experienced and responded to fair and unfair events. In Experiment 3, therefore, we ensured that the fairness manipulation was directly experienced by participants in an experimental paradigm that is often used for this purpose (see, e.g., Van den Bos, 2001; Van den Bos et al., 1997; Van den Bos \& Miedema, 2000; Van den Bos et al., 2005). Furthermore, in this paradigm we induced the most generally accepted and best-documented manipulation in procedural justice experiments: participants were or were not allowed an opportunity to voice their opinions about a decision to be made (see, e.g., Brockner et al., 1998; Folger et al., 1979; Lind, Kanfer, \& Earley, 1990; Van den Bos, 2001; Van den Bos et al., 1997).

In the experiment, before manipulating the voice vs. novoice procedures, participants were asked to look for $1 \mathrm{~min}$ at their computer screens and during this minute either an exclamation point was presented or a line with a dot on top of it (so that participants looked at the same stimuli but in one condition implying an exclamation point and in the other condition not implying an exclamation point). Our main prediction again was that participants' procedural justice judgments would be more strongly affected by the procedure manipulation in the exclamation point condition than in the scrambled exclamation point condition. In Experiment 3, we again were interested to see whether participants would be faster in their procedural justice judgment responses when primed with the exclamation point than when not primed with the exclamation point.

\section{Method}

\section{Participants and design}

One hundred and eighty-six students (40 men and 146 women) at Utrecht University participated in the experiment and were paid for their participation. Participants were randomly assigned to one of the conditions of the 2 (characters: exclamation point vs. scrambled exclamation point) $\times 2$ (procedure: voice vs. no voice) factorial design . One participant had difficulty understanding the stimulus materials, being a non-native speaker, and had to be excluded from the data set. Unfortunately, anonymous debriefing interviews, conducted after people participated in the study, suggested that in this experiment there may well have been a few participants who did not participate in a serious manner in the experiment. Following recommendations by various statistical handbooks (e.g., Cohen, Cohen, West, \& Aiken, 2003; Tabachnick \& Fidell, 1989), we checked whether outliers indeed were present in our data set. To this end, we followed a procedure sug- gested by Cohen et al. (2003) and calculated Cook's distance measure (see Cook, 1977; see also Cohen et al., 2003) to assess whether some of the participants did in fact show statistically strange reactions on our main dependent variables (procedural justice judgments). This analysis indeed revealed that 10 of the remaining 185 participants could be identified as outliers. ${ }^{5}$ We dropped these participants, leaving 175 participants ( 37 men and 138 women) in our final data set, with 43 or 44 participants in each of the four conditions of Experiment 3.

\section{Experimental procedure}

The experimental procedure was the same as in Experiments 1 and 2, except for the below-mentioned points, and closely followed the experimental paradigm used in earlier experiential justice studies (see, e.g., Van den Bos, 2001; Van den Bos et al., 1997; Van den Bos \& Miedema, 2000; Van den Bos et al., 2005). The experiment lasted a total of $40 \mathrm{~min}$ and participants were paid 4 Euros for their participation. In the first part of the instructions, participants were informed that they participated in the study with another person, referred to as Other. Participants were also told that the computers were connected to one another and that the experimenter could communicate with them by means of the computer network. The experimental procedure was then outlined to the participants: after the experimental tasks were explained, participants would practice the tasks for $2 \mathrm{~min}$, after which time they would work on the tasks for $10 \mathrm{~min}$. Furthermore, participants were informed that, after all participants were run, a lottery would be held among all participants. The winner of this lottery would receive 50 Euros. (Actually, after all participants had completed the experiment, the 50 Euros were randomly given to one participant; a procedure to which none of the participants objected upon debriefing.) Participants were told that a total of 200 lottery tickets would be divided among all participants. Furthermore, participants were told that after the work round the experimenter would divide some lottery tickets between them and Other. Several practice questions were posed to ensure comprehension of the lottery. If participants gave a wrong answer

\footnotetext{
5 These 10 participants constituted 5 percent of our initial data set, and consisted of 3 men and 7 women, randomly distributed among our conditions, with 2 or 3 participants per condition. Retaining these participants in our data set still yielded a stronger procedure effect on participants' procedural justice judgments in the exclamation point condition, $F(1,181)=123.66, p<.001, \eta^{2}=.41$, than in the scrambled exclamation point condition, $F(1,181)=103.87, p<.001, \eta^{2}=.37$, although we should note explicitly that this pattern of findings was definitely weaker than the pattern we obtained when these participants were not included in our data analyses (see Results section). Keeping the participants in the data set still indicated that in the scrambled exclamation point condition, participants' procedural justice judgments were more positive following the voice procedure $(M=5.35, S D=1.30)$ than following the no-voice procedure $(M=2.94, S D=0.93)$, and that in the exclamation point condition the difference between the voice $(M=5.39, S D=1.09)$ and no-voice $(M=2.75, S D=1.21)$ conditions was even greater.
} 
to a question, the correct answer was disclosed and main characteristics of the lottery were repeated.

The experimental tasks were then explained to the participants. Figures would be presented on the upper right part of the computer screen. Each figure consisted of 36 squares, and each square showed one of eight distinct patterns. On the upper left side of the computer screen one of the eight patterns would be presented, and participants had to count the number of squares with this pattern in the figure on the right side of the screen. When participants had indicated the correct number of patterns in the figure on the right side of the screen, another figure and another pattern would be presented on the screen. In both the practice round and the work round, the number of figures that the participant had counted constituted the number of tasks that the participant had completed. Furthermore, in both rounds, the number of tasks completed was presented on the lower right side of the screen. On the lower left side of the screen the time remaining in the present round was shown.

The practice round then began, after which the work round began. After the work round had ended, participants were told how many tasks they had completed in the work round, and-in order to ensure that participants compared themselves to Other - it was communicated to the participant that Other had completed an equivalent number of tasks. To assess whether participants thought of Other as a person who was comparable in the amounts of inputs he or she provided (cf. Van den Bos et al., 1997), they were asked to what extent Other had performed well in the work round relative to the performance of the participant self $(1=$ much worse, $4=$ equally, $7=$ much better $)$ and to what extent Other was good in performing the tasks in the work round relative to the participant self $(1=$ much worse, $4=$ equally, $7=$ much better . After this, participants were asked to think for $1 \mathrm{~min}$ about the percentage of lottery tickets that they should receive relative to Other.

As has been done in earlier justice studies (e.g., Van den Bos, 2001; Van den Bos \& Miedema, 2000; Van den Bos et al., 2005), participants were then told that before the experimenter would divide the lottery tickets between them and Other, they would be asked to complete a different task, and that after they would have completed this task, the study would continue. The characters manipulation was then manipulated. The exclamation point condition was the same as in Experiments 1 and 2. In the scrambled exclamation point condition of Experiment 3, the following set of characters were presented for $1 \mathrm{~min}$ at the center of participants' screens:

After this, all participants completed the PANAS, with both the positive and negative subsets again yielding reliable scales $(\alpha$ 's $=.88$ and .82 , respectively). After they had completed the PANAS, all participants were told that by pushing the return button on the keyboard the study would continue.
The procedure was then manipulated in the same way as in earlier procedural justice experiments (e.g., Van den Bos, 2001; Van den Bos et al., 1997; Van den Bos \& Miedema, 2000; Van den Bos et al., 2005). In the voice condition, the experimenter allegedly asked participants, by means of the computer network, to type in their opinion about the percentage of tickets that they should receive relative to Other. (In reality, however, all stimulus information was preprogrammed.) Participants in the no voice condition were informed that they would not be asked to type their opinion about the percentage of tickets that they should receive relative to Other.

After this, participants were asked questions pertaining to the dependent variables and manipulation checks. The same procedural justice judgment scale as in Experiment 1 was assessed $(\alpha=.97)$. Again, the time that participants needed to answer the procedural justice judgments was measured by the computers. ${ }^{6}$ In addition, following previous procedural justice studies (e.g., Van den Bos, 2001; Van den Bos et al., 1997), the manipulation of procedure was further checked by asking participants to what extent they agreed with the statement that they had been given an opportunity to voice their opinion about the percentage of tickets that they should receive relative to Other $(1=$ strongly disagree, $7=$ strongly agree $)$ and to what extent they agreed with the statement that they had not been given an opportunity to voice their opinion about the percentage of tickets that they should receive relative to Other $(1=$ strongly disagree, $7=$ strongly agree). After this, participants were paid for their participation and were thoroughly debriefed. During the debriefing procedure, participants indicated that they did not perceive a direct relationship between the characters manipulation and their reactions to the voice or no voice procedures. Participants were not suspicious about our manipulations and did not object to the experimental procedure used in the experiment.

\section{Results}

\section{Manipulation checks}

As in Experiments 1 and 2, a $2 \times 2$ ANOVA on the response latencies scale showed a main effect of the characters manipulation, $F(1,170)=25.26, p<.001$. Participants in the exclamation point condition responded significantly faster to the procedural justice questions $(M=3.89 \mathrm{~s}$, $S D=1.72$ s) than participants in the scrambled explanation point condition $(M=5.36 \mathrm{~s}, S D=1.80 \mathrm{~s})$. In addition, the findings showed a significant main effect of the procedure manipulation, $F(1,170)=4.84, p<.03$, indicating that par-

\footnotetext{
${ }^{6}$ The response latencies of 1 participant $(M=19.23)$ were three standard deviations above the overall mean $(M=4.70, S D=2.19)$. Using the same statistical procedures as in Experiments 1 and 2, the response latencies of this participant were discarded, logarithmic transformations were applied to the remaining response latencies, and participants' transformed response latencies were averaged to form a reliable scale of their response latencies $(\alpha=.75)$.
} 
ticipants in the no-voice condition responded faster to the procedural justice questions ( $M=4.32 \mathrm{~s}, S D=1.89 \mathrm{~s})$ than those in the voice condition $(M=4.92 \mathrm{~s}, S D=1.88 \mathrm{~s})$. This suggests that sometimes unfair procedures (such as no-voice procedures) may be responded to in faster ways than fair procedures (such as voice procedures). The interaction effect was not significant.

A $2 \times 2$ MANOVA on the two manipulation checks of procedure (the voice check and the no-voice check) yielded only a main effect of procedure at both the multivariate level and the univariate levels: multivariate $F(2,170)=208.78$, $p<.001$; for the voice check, $F(1,171)=342.82, p<.001$; for the no-voice check, $F(1,171)=291.94, p<.001$. Participants in the voice condition agreed more with the statement that they received an opportunity to voice their opinion $(M=6.10, S D=1.13)$ than participants in the no-voice condition $(M=2.01, S D=1.73)$. Participants in the no-voice condition agreed more with the statement that they did not receive an opportunity to voice their opinion $(M=5.72$, $S D=1.81)$ than those in the voice condition $(M=1.77$, $S D=1.22$ ). In correspondence with earlier studies (e.g., Van den Bos, 2001; Van den Bos et al., 1997; Van den Bos \& Miedema, 2000; Van den Bos et al., 2005), these findings suggest that the procedure manipulation was successfully operationalized.

\section{PANAS}

A $2 \times 2$ MANOVA on the positive and negative subsets of the PANAS yielded no effects at both the multivariate and univariate levels. This suggests that differences in affective states cannot explain the findings reported here. Overall means of the positive and negative subsets were 2.51 $(S D=0.71)$ and $1.30(S D=0.36)$, respectively. Furthermore, after applying the appropriate Bonferroni adjustment (see Hays, 1981), a $2 \times 2$ MANOVA on all the 20 PANAS items did not yield any significant effects, suggesting that in Experiment 3 specific affective reactions were not influenced by our exclamation point manipulation.

\section{Comparability measures}

As expected, participants' comparability judgments yielded no significant effects at both the multivariate level and the univariate levels in a $2 \times 2$ MANOVA. Participants indicated that the other participant had performed equally well in the work round $(M=3.99, S D=0.34)$ and was equally good in performing the tasks $(M=3.95$, $S D=0.39$ ). Thus, participants thought of the other person as a comparable person with respect to the tasks that were completed in the experiment.

\section{Percentage findings}

Participants who were allowed voice $(n=87)$ typed in their opinion about the percentage tickets that they should receive relative to the other participant. A one-way ANOVA yielded no significant effect of the characters manipulation. Inspection of the means indicated that participants typed in that the lottery tickets should be divided equally between themselves and the other participant: 80 participants answered that they should get $50 \%$ of the tickets and the mean percentage was $52.54 \%(S D=10.59)$. These findings are supportive of equity theory (see, e.g., Adams, 1965): participants preferred to divide outcomes equally between themselves and the other participant (who contributed an equal amount of inputs, and who hence deserved-according to equity theory-to receive the same amount of outputs as the participants themselves).

\section{Dependent variables}

Participants' procedural justice judgments indicated a main effect of procedure, $F(1,171)=240.04, p<.001$, and the predicted interaction effect, $F(1,171)=3.93, p<.05$. The main effect of the characters manipulation was not significant. Fig. 3 shows these effects. As hypothesized, the results indicated that the simple main effect of the procedure manipulation was stronger in the exclamation point condition, $F(1,171)=153.57, p<.001, \eta^{2}=.47$, than in the scrambled exclamation point condition, $F(1,171)=90.69, p<.001, \eta^{2}=.35$. This indicates that in the scrambled exclamation point condition, participants' justice judgments were more positive following the voice procedure $(M=5.24, S D=1.27)$ than following the novoice procedure $(M=3.03, S D=0.88)$. Moreover, in the exclamation point condition the difference between the voice $(M=5.49, S D=1.02)$ and no-voice $(M=2.64$, $S D=1.11)$ procedure conditions was even greater.

The characters manipulation did not yield statistically significant effects within both the voice and the no-voice conditions. This said, it can be noted here that the simple main effect of the characters manipulation was marginally significant within the no-voice condition, $F(1,171)=2.94$, $p<.09$, whereas such a trend was not found within the voice condition, $F(1,171)=1.48, p>.22$. We will return to these results in the General discussion.

\section{Discussion}

After manipulating procedural accuracy in Experiment 1 and outcome valence in Experiment 2, Experiment 3 varied that participants directly experienced voice or no-voice procedures. In correspondence with our predictions, we

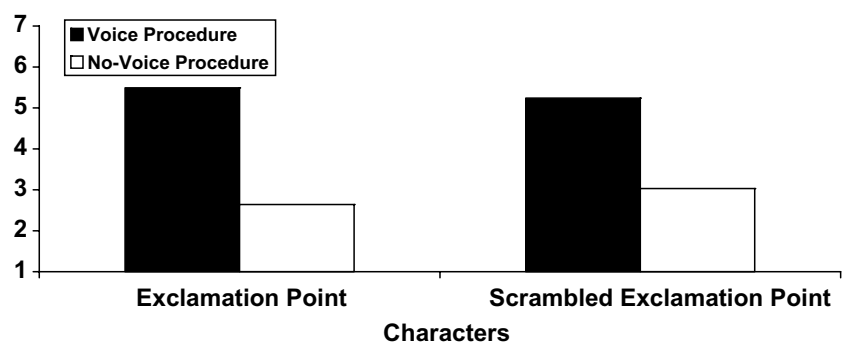

Fig. 3. Mean procedural justice judgments as a function of the characters and procedure manipulations of Experiment 3. Means are on 7-point scales, with higher values indicating higher levels of judgments of procedural justice. 
found that procedural justice judgments were more extreme when participants had been primed with an exclamation point as opposed to a scrambled exclamation point. Furthermore, participants were faster in giving their procedural justice judgments in the exclamation point condition than in the scrambled exclamation point condition. Participants were faster also to give their procedural justice judgments when responding to the no-voice procedures than when reacting to the voice procedures, perhaps suggesting that negative procedures that people directly experience (as opposed to only read about; cf. Experiment 1) may impact the justice judgment process more than positive procedures do.

Taken together, the findings of Experiments 1-3 suggest that presenting large exclamation points for some time to people may lead to more extreme and more vigilantly constructed justice judgments. It could be argued that after having presented the results of these studies it is important to know (1) what the exclamation points primed and (2) whether evidence for our alarm-system predictions could also be found when we would present different alarm-related stimuli to people that are more directly related to alarming conditions people may encounter in everyday life. Our fourth full experiment was designed to address the latter point.

With respect to the former point of getting more information on what exclamation points prime, we can refer here to a line of research using functional magnetic resonance imaging (fMRI) testing that some of us recently started (Van den Bos \& Rijpkema, 2007). The data collected thus far suggest that watching an exclamation point especially leads to activation of a part of the medial frontal gyrus (Brodmann area [BA] 9). Interestingly, this area is also found to be active when people are performing personal moral judgment tasks and is known to be sensitive to tapping the combined effects of cognitive and emotional responses (Greene, Nystrom, Engell, Darley, \& Cohen, 2004; Greene, Sommerville, Nystrom, Darley, \& Cohen, 2001). This may indicate that a combination of cognition and emotion best predicts how people form justice judgments and make personal moral decisions. In other words, the social psychology of justice and personal moral judgments may well involve hot cognitive, not cold cognitive, processes (Van den Bos, in press). Future research is needed to pursue this line of research and line of thinking in more detail.

\section{Experiment 4}

After having found evidence for our line of reasoning in controlled laboratory studies that showed that subtle representations of the alarm system (i.e., exclamation points) are sufficient to elicit more extreme justice judgments of fair and unfair procedures and outcomes, we sought to test our line of reasoning outside the psychology lab using a different set of alarming stimuli that may be more directly related to, and may have more face validity with respect to alarming conditions people may encounter in everyday life. Specifically, in Experiment 4 we used a flashing light of the sort used on emergency vehicles or to warn for road hazards, and as our alarm-related manipulation we varied whether the flashing light had or had not been switched on.

Participants of Experiment 4 were people from various parts of The Netherlands, with different educational backgrounds, and from different age groups, who were interviewed in a shopping area of a medium-sized city located in the middle of The Netherlands. Building and extending on Experiment 2, we again varied that participants received a good or a bad outcome, but this time the outcome that participants themselves received was held constant and we varied whether a comparable other person received an outcome that was either equal or better than the outcome of the participants themselves (cf. Van den Bos et al., 1997). Our main dependent variables were participants' justice outcome judgments. Because in Experiment 4 our stimulus materials were presented in paper-and-pencil format to our participants, we could not reliably assess participants' response latencies in this experiment and that is why we checked in Experiment 4 whether participants reported that they became more alert as a result of the flashing light manipulation.

\section{Method}

\section{Participants and design}

One hundred and eighty individuals (95 women) participated in the experiment and were randomly assigned to one of the conditions of the 2 (flashing light: on vs. off) $\times 2$ (outcome: good vs. bad) factorial design. Forty-five participants took part in each of the four conditions.

Participants were interviewed in the shopping area of the city center of Amersfoort, a medium-sized city in the middle of The Netherlands that attracts customers from different parts of the country. Indeed, our participants came from various provinces of The Netherlands (Flevoland, Gelderland, Groningen, Noord Holland, Overijssel, and Utrecht). Mean age of the participants was 30.92 years ( $S D=14.56)$, with the youngest participant being 14 years old and the oldest participant being 78 years old. Twenty percent of the participants had completed a lower form of education ( $L O, L B O, V M B O, M A V O$ ), $40 \%$ had completed a middle-level form of education ( $M B O, H A V O)$, $31 \%$ had completed a higher form of education ( $H B O$, $V W O$ ), and $8 \%$ had completed a university degree $(W O)$.

\section{Experimental procedure}

People who were walking in the shopping area of the city center of Amersfoort were asked whether they would like to participate in a study on how people process information and which would take a maximum of $10 \mathrm{~min}$ of their time. Two meters behind the experimenter, an orange flashing light of $17 \times 14 \times 14 \mathrm{~cm}$ had been placed on a small pedestal of $1 \mathrm{~m}$ high. Both the flashing light and pedestal were ostensibly unrelated to our study and the flashing light was connected by means of an electric cable of $1.5 \mathrm{~m}$ long to a large store (Vroom \& Dreesmann; a Dutch 
equivalent of Macy's). To induce the flashing light manipulation, the flashing light had been switched on for half of the participants and the flashing light was off for the other half of the participants.

At the beginning of the experiment, the experimenter handed participants a questionnaire that contained the stimulus materials with which we induced the outcome manipulation of Experiment 4 and with which we measured the dependent variables and manipulation checks of the study. Comparable to Experiments 1-3, all participants first completed the PANAS, with both the positive and negative subsets again yielding reliable scales (both $\alpha$ 's $=.82$ ). After this, all participants were asked to imagine the following situation:

You are working at a prestigious ICT company. Together with a colleague you have been working on an assignment for one of the most important clients of the company. The amount of duties you and your colleague have to perform is equal to each other and you both enjoy working together. You and your colleague are working equally hard on the assignment and after one month the assignment is completed successfully. The client is very satisfied with the work you and your colleague have performed. This is reason for your boss to give you both a bonus. You and your colleague are comparable in the number of years you are working at the company as well as in age and salary.

This was followed by the manipulation of outcome. Participants read the sentence (manipulated information in italics):

You get a bonus of 300 Euros. Your colleague later tells you that he received a bonus of 300/500 Euros.

The dependent variables and manipulation checks were then measured. Building on Experiments 1-3, participants' judgments of outcome justice were assessed by asking participants how just $(1=$ very unjust, $7=$ very just $)$, appropriate $(1=$ very inappropriate, $7=$ very appropriate $)$, and justified $(1=$ very unjustified, $7=$ very justified $)$ they considered the bonus that they received. Participants' answers to these three items were averaged to form a reliable scale of their outcome justice judgments $(\alpha=.96)$.

At the end of the experiment, we checked whether participants became more on their alert as a result of the flashing light manipulation: we asked participants whether they noticed the flashing light (all participants in all conditions reported that they did) and then we asked participants whether the flashing light led them to be alert $(1=$ very weakly, $7=$ very strongly $)$ and to be attentive $(1=$ very weakly, $7=$ very strongly). Participants' answers to these two items were averaged to form a reliable scale of participants' alertness $(\alpha=.83)$. We also assessed whether, instead of, or in addition to, increasing alertness, the flashing light manipulation increased participants' levels of agitation: participants were asked whether the flashing light made them feel agitated $(1=$ very weakly, $7=$ very strongly $)$ and tense $(1=$ very weakly, $7=$ very strongly $)$. Participants' answers to these two items were averaged to form a reliable scale of agitation $(\alpha=.96)$. After this, participants were debriefed. Participants were not suspicious about our manipulations and did not object to the experimental procedure used in the experiment.

\section{Results}

\section{Manipulation check}

A $2 \times 2$ ANOVA on the alertness scale showed a main effect of the flashing light manipulation only, $F(1,169)=9.18, p<.01 .^{7}$ This showed that participants in the condition where the flashing light was switched on indicated to be more alert $(M=2.11, S D=1.31)$ than participants in the condition where the flashing light was switched off $(M=1.56, S D=1.09)$.

It can also be noted here that a $2 \times 2$ ANOVA did not yield significant effects on the agitation measure, indicating that the flashing light manipulation did not affect participants' level of agitation, $F(1,168)=0.12, p>.73$ (overall $M=1.24, S D=0.69)$. These findings suggest that the flashing light manipulation reliably affected alertness whereas it did not reliably influence agitation. We will discuss the implications of these findings in the General discussion.

\section{PANAS}

As in Experiments 1-3, a $2 \times 2$ MANOVA on the positive and negative subsets of the PANAS yielded no effects at both the multivariate and univariate levels. This suggests that overall affective states cannot explain the findings reported here. Overall means of the positive and negative subsets were $2.85(S D=0.67)$ and 1.46 $(S D=0.51)$, respectively. Furthermore, after applying the appropriate Bonferroni adjustment (see Hays, 1981), a $2 \times 2$ MANOVA on all the 20 PANAS items did not show significant effects, suggesting that in Experiment 4 specific affective reactions were not influenced by our flashing light manipulation.

\section{Dependent variables}

Participants' outcome justice judgments indicated a main effect of outcome, $F(1,176)=307.43, p<.001$, as well as the predicted interaction effect, $F(1,176)=5.11, p<.03$. The main effect of the flashing light manipulation was not significant. Fig. 4 illustrates these effects. As hypothesized, results showed that the simple main effect of the outcome manipulation was stronger in the condition where the flashing light was switched on, $F(1,176)=195.92, p<.001$, $\eta^{2}=.53$, than in the condition where the flashing light was switched off, $F(1,176)=116.63, p<.001, \eta^{2}=.40$. These findings indicate that in the condition where the

\footnotetext{
${ }^{7}$ Responses of some participants were missing on the alertness and agitation measures ( $n$ 's $=8$ and 9 , respectively), causing the degrees of freedom in the analyses of variance reported on these two measures.
} 


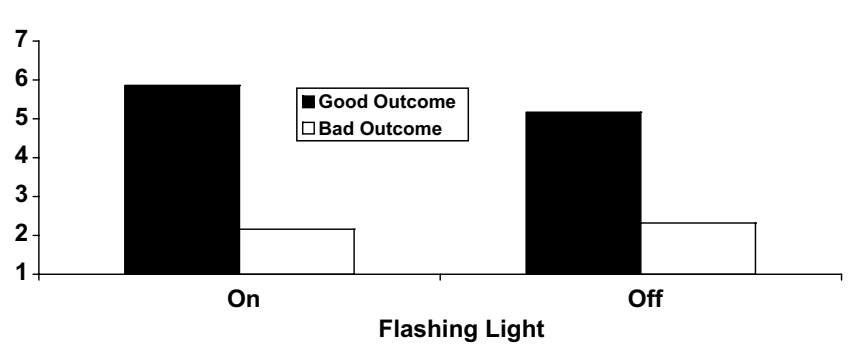

Fig. 4. Mean outcome justice judgments as a function of the flashing light and outcome manipulations of Experiment 4. Means are on 7-point scales, with higher values indicating higher levels of judgments of outcome justice.

flashing light was switched off, participants' justice judgments were more positive following the good outcome $(M=5.17, S D=1.56)$ than following the bad outcome $(M=2.32, S D=1.15)$. Furthermore, in the condition where the flashing light was switched on, participants' outcome justice judgments differed even more between the good $(M=5.86, \quad S D=1.18)$ and bad $(M=2.16$, $S D=1.05$ ) outcomes.

The flashing light manipulation yielded a significant simple main effect within the good outcome condition, $F(1,176)=6.81, p<.02$, and a nonsignificant effect within the bad outcome condition, $F(1,176)=0.35, p>.55$. We will return to this finding in the General discussion.

\section{General discussion}

Building and extending on the human alarm system literature, we reasoned in the current paper that we would obtain strong evidence for our line of reasoning if viewing large exclamation points prior to making evaluations of the justice of accurate or inaccurate procedures (Experiment 1), good or bad outcomes (Experiment 2), and voice or no-voice procedures (Experiment 3) would yield the hypothesized effects on participants' justice judgments and their response latencies. The findings of Experiments 1-3 supported our hypotheses. Furthermore, Experiment 4 extended these findings by showing that a flashing warning light produced similar effects on outcome justice judgments and perceived alertness among participants with various educational backgrounds and from different age groups who were walking in a shopping center of a typical Dutch city. That is, in correspondence with the alarm-system view of the justice judgment process presented in this paper, the findings of Experiment 4 reveal that the mere presence of a flashing light that has been switched on can lead people to show more extreme justice judgments in response to variations in good and bad outcomes. Also, participants in the conditions where the flashing light had been switched on indicated that they felt they were more alert than those in the conditions where the flashing light was switched off.

Taken together, the findings of the experiments presented here suggest that the presence of alarming stimuli, such as exclamation points (Experiments 1-3) and flashing lights (Experiment 4), indeed can lead to more extreme justice judgments about subsequently experienced procedures (Experiments 1 and 3) and outcomes (Experiments 2 and 4), not only when reacting to justice scenarios (Experiments 1,2 , and 4), but also when assessed in a more experiential context (Experiment 3), and not merely in controlled laboratory studies (Experiments 1-3), but also when encountered in a more real-life context (Experiment 4).

The juxtaposition of the alarm system and justice literatures presented here is a strength of the current paper, we think, but a reader may wonder why the vigilance, provoked by the alarm system, resulted in more extreme judgments rather than more nuanced judgments. We think there may be three good reasons for this. The first reason why we predicted this effect was that our review of the human alarm and justice judgment literatures indicated that the same conditions that activate the human alarm system also lead to more extreme justice judgments. This suggested to us that if we would activate the human alarm system directly by presenting alarm-related stimuli to people, this might well lead to more extreme judgments about subsequently presented justice-related procedures and outcomes. The findings of Experiments 1-4 are in accordance with this line of reasoning.

The second reason is that although alarming conditions may sometimes instigate contemplation or introspection in human beings (cf. Bechara, 2005), we argue that most alarming situations do not allow for contemplation and introspection, but instead require that people respond rather quickly to what is going on. Thus, we do not rule out that contemplation, and hence slower reaction times and perhaps more nuanced judgments sometimes may be the result of an activated alarm system, but we also argue that the more common response may be faster and more extreme reactions. The findings presented in this paper seem to support the conclusion that this is a more likely reaction. Of course, we would applaud future research that would show more contemplation in alarming situations. Very interesting in this respect are some very recent findings reported by Eisenberger and Lieberman (in press) that suggest that people who score high in dispositional selfconsciousness may react with more controlled, as opposed to more intuitive, responses to an activated alarm system.

The third reason is that modern justice judgment research and recent justice theories suggest that how people typically form judgments of justice and morality may in fact be best understood by focusing on intuitive processes (Haidt, 2001), affective-experiential states (Maas \& Van den Bos, submitted for publication), spontaneous inferences (Ham \& Van den Bos, submitted for publication), self-related thoughts (Loseman, Van den Bos, \& Ham, 2006), and self-defensive processes (Van den Bos, Miedema, \& Vermunt, submitted for publication). In other words, people seem to form their justice judgments in rather reflexive ways, as opposed to reflecting carefully on how to form these judgments (cf. Lieberman, 2003; Lieberman, Gaunt, 
Gilbert, \& Trope, 2002; Strack \& Deutsch, 2004). This suggests to us that the justice judgment process may be especially sensitive to reflex-related aspects of alarm-related stimuli, rather than to reflection-related aspects of the human alarm system (cf. Lieberman, 2003), leading them to respond faster and with more extreme judgments in alarming situations. This possible implication of the current paper seems to us to deserve further investigation.

The specific pattern of effects on people's justice judgments in the four studies also deserves some reflection here. That is, as noted in the Results sections, in three out of four studies (Experiments 1, 2, and 4), our findings suggested that it may be especially in people's reactions to fair events, such as accurate procedures (Experiment 1) and good outcomes (Experiments 2 and 4), that alarm-related manipulations have their effect on people's justice judgments. This finding is in accordance with the view that, after the alarm system has been activated, people may react particularly positively to the experience of fair events as the relational quality and inclusion message conveyed by fair treatment and other fair experiences (cf. Lind, 2001; Leung et al., 2004; Tyler \& Lind, 1992) may signal the soothing message that threats are manageable or that there is less reason for alarm than initially felt. In other words, experiences of fair events may switch an activated alarm system from "Code Red" back to "Code Orange" or "Code Green."

This said, it should also be noted explicitly that in Experiment 3 the exclamation point manipulation did not show statistically significant effects of the exclamation point manipulation within both the voice and no-voice conditions, and in fact was marginally significant within the no-voice condition whereas such a trend was not found within the voice condition. Moreover, when we pooled results across Experiments 1-4, then the effects of the alarm manipulations were significant within both the fair and the unfair conditions, although the effect was somewhat stronger in the fair conditions, $F(1,534)=15.27, p<.001$, $\eta^{2}=.03$, than in the unfair conditions, $F(1,534)=4.51$, $p<.04, \eta^{2}=.01$. An interesting topic for future research would be to sort out whether alarm-related manipulations generally have more impact on how people react to fair events than on how they respond to unfair events and, if so, to further explore the precise psychological mechanisms that may explain this differential impact.

\section{Implications}

The importance of exclamation points and flashing lights as important alarm-related cues that moderate the justice judgment process has not been considered before in the justice literature. Furthermore, to the best of our knowledge, the possible impact of exclamation points and flashing lights on human judgment processes in general has not been studied before in the alarm-system literature (for reviews, see, e.g., Carter et al., 2000; Eisenberger \& Lieberman, 2004; Eisenberger et al., 2003; Klein, 1996; Liddell et al., 2005; Lieberman \& Eisenberger, 2004; Tillfors,
2004; see also Elliot, Maier, Moller, Friedman, \& Meinhardt, in press). This attests to the new contribution of the line of reasoning presented here and indicates the possible importance of the current findings for the literatures on human judgments in general and justice judgments in particular.

Furthermore, our findings may be important precisely because they raise the possibility that not only justice judgments but also other social judgments might be influenced by the presentation of stimuli like exclamation points or flashing lights. Previous justice theories have tended to assume that there is something unique about the justice concept; something that makes the process of how justice judgments are formed stand apart compared to the processes with which people form judgments of other constructs (see, e.g., Lerner, 1977, 1980, 2003; Montada, 1998, 2002; see also Cropanzano, Goldman, \& Folger, 2003; Folger, 1984, 2001; Folger, Cropanzano, \& Goldman, 2005; Mikula, 2005). Our conjecture is that justice may sometimes have unique qualities and that it may sometimes not. A challenge for future justice research is to find out the conditions under which the justice judgment process shows unique aspects and when it does not. An important, indeed a theoretically exciting aspect of the current findings is that they suggest that justice judgments conform to other alarm-related judgments (see, e.g., Eisenberger \& Lieberman, 2004; Eisenberger et al., 2003; Lieberman \& Eisenberger, 2004; Murray et al., 2002, 2005).

More generally, although we truly appreciate and value the attempts in the justice literature to study what makes the psychology of the justice concept different from the psychology of other concepts, in the current paper we argue that this may have come at the expense of relative neglect for a thorough examination of the basic processes that also may play a pivotal role in how people form justice judgments. Therefore, we have explicitly focused here on the basics of the justice judgment process. Indeed an important implication of the findings presented here is that they suggest that the justice judgment process may share important similarities with the processes that determine other human judgments and responses. In investigating this issue, one aim of this paper was to show that the justice judgment process may be affected by sometimes subtle cues in people's environments; cues that may not have been revealed when one would have studied justice judgments as being something unique, compared to other human judgments.

From the literature on arousal it seems unlikely that physiological arousal has been affecting strongly the effects of our exclamation point manipulations on participants' reactions to the subsequent procedures or outcomes of Experiments 1-3 (see, e.g., Lang, Greenwald, Bradley, \& Hamm, 1993). Specifically, the arousal literature suggests that physiological arousal effects in response to minimal manipulations (like the exclamation point manipulation we used in Experiments 1-3) in all likelihood will have disappeared after $1 \mathrm{~min}$ (see, e.g., Lang et al., 1993). Given the fact that we used the 20-items PANAS questionnaire as our 
filler tasks (which clearly took longer than $1 \mathrm{~min}$ to complete) it seems unlikely that physiological arousal can explain the findings reported here. Furthermore, the findings reported in Experiment 4 suggest that the flashing light manipulation did not affect perceived agitation and, as intended with this manipulation, did influence perceived alertness. These findings are in correspondence with what we intended with our manipulations, but of course we would applaud further research on these important issues. Interesting in this respect is that in Experiment 2 we found an effect of our exclamation point manipulation on the PANAS item that assesses excitement, such that participants felt more excited in the exclamation point condition than in the scrambled exclamation point condition. This effect was only found in one of our four experiments and when we controlled for participants' excitement scores participants' outcome justice judgments still showed a stronger effect of the outcome manipulation in the exclamation point condition than in the scrambled exclamation point condition. This said, we explicitly encourage future research to further examine the psychological processes which alarm-related manipulations may prime.

Another interesting implication that may follow from an alarm-system view of the justice judgment process involves the possible distinctions between alarm activations that occur prior to the justice judgment process and those that occur within the justice judgment process. In the current studies, the human alarm system was activated by events that happened before the justice judgment process occurred. An alternative sequence of events is that the alarm system could be activated as a result of events that happen during the justice judgment process. The former would constitute justice-exogenous activation of the alarm system and the latter justice-endogenous activation. An example of the latter may be being treated in an unfair manner by your new supervisor in an important meeting, an alarming experience that might augment the effect of the experience on justice judgments. Endogenous activation would lead people to alertly process what is going on, how to make sense of this, and to be more alert in subsequent interactions with the supervisor.

It might be the case that justice-exogenous and justiceendogenous alarm-related factors are differentially related to fair and unfair events. For example, perhaps, as a result of either socialization (e.g., Lerner, 1977, 1980) or evolutionary processes (De Waal, 1996), people have learned to rely on fair treatment to cope with exogenous alarminducing events (cf. the current findings). In contrast, experiences of unfair treatment might activate justiceendogenous alarm systems that then augment the processing of the unfair treatment information that stimulated the alarm. This would suggest that experiences of unfair events may serve as wake-up calls whereas fair events may calm people down. To carry the logic of this line of thought one step further, unfair experiences would then have special relevance in relatively calm situations, in which the alarm system is not very active, whereas fair events have an especially important social function in times when the alarm system has already been activated. Future research is obviously needed to test these interesting yet speculative implications of the current research.

Now that the current findings have been found in the pioneering studies presented here, future research can start to test the implications of our findings in studies that have higher levels of ecological validity. For example, future research might assess how people react to fair and unfair treatment by their management when the business context may make the human alarm system more vs. less active. Furthermore, now that evidence has been obtained for the important role that alarm-related symbols may have in the social psychology of justice, future theoretical work can explore the implications of these findings for other justice theories, such as group-value (e.g., Lind \& Tyler, 1988), just world (e.g., Lerner, 1977, 1980; Hafer, 2000), and moral virtue (e.g., Cropanzano et al., 2003; Folger, 2001; Folger et al., 2005) explanations of social justice. Perhaps revisiting these theories in light of our findings will reveal that groups, just world beliefs, and/or ideas about mortal virtues are important to people because these issues may activate human alarm systems or help people to manage already activated alarm systems.

Related to this, as noted earlier, the studies reported here were in part inspired by the conjecture that uncertainty management findings reported in the justice literature (see, e.g., Van den Bos, 2001; Van den Bos \& Lind, 2002; Van den Bos et al., 2005) may be explained by the notion that experiences of personal uncertainty may often constitute alarming events to people and that it is this alarm-related component of uncertainty manipulations that may be largely driving uncertainty effects reported in the social psychological literature (Hogg, 2005; McGregor et al., 2001; Murray et al., 2002). Furthermore, Brockner and Wiesenfeld (1996) observed that fairness effects are often stronger in the presence of negative outcomes. Because under most circumstances negative outcomes are more likely than positive outcomes to activate the human alarm system, the outcome-based moderation that Brockner and Wiesenfeld observed may be a special case of the more general moderation of fairness effects by alarmrelated stimuli. These are all speculative remarks, of course, but these speculations as well as the future studies that may follow from them, now have been made possible by means of the research presented here and these speculations may well give rise to new, more powerful social justice theories.

\section{Conclusions}

The question of how people form justice judgments has fascinated and puzzled philosophers and social theorists for centuries. In the current paper, a new social psychological hypothesis on this issue was put forward focusing on the human alarm system as a potential moderator of the justice judgment process. Building and extending on this basic hypothesis, we proposed that the presentation of exclama- 
tion points or flashing lights would reliably lead to more extreme judgments about subsequent justice-related events. Our findings indeed provide support for this line of reasoning. It is our hope that the theoretical implications of the line of reasoning and findings presented here will further social psychologists' understanding of the justice judgment process and may contribute to the growing literature on the human alarm system.

\section{References}

Adams, J. S. (1965). Inequity in social exchange. In L. Berkowitz (Ed.). Advances in experimental social psychology (Vol. 2, pp. 267-299). New York: Academic Press.

Barrett-Howard, E., \& Tyler, T. R. (1986). Procedural justice as a criterion in allocation decisions. Journal of Personality and Social Psychology, 50, 296-304.

Bechara, A. (2005). Decision making, impulse control and loss of willpower to resist drugs: A neurocognitive perspective. Nature Neuroscience, 8, 1458-1463.

Blau, P. M. (1964). Exchange and power in social life. New York: Wiley.

Brockner, J., Heuer, L., Siegel, P. A., Wiesenfeld, B., Martin, C., Grover, S., et al. (1998). The moderating effect of self-esteem in reaction to voice: Converging evidence from five studies. Journal of Personality and Social Psychology, 75, $394-407$.

Brockner, J., \& Wiesenfeld, B. M. (1996). An integrative framework for explaining reactions to decisions: Interactive effects of outcomes and procedures. Psychological Bulletin, 120, 189-208.

Callejas, A., Lupianez, J., \& Tudela, P. (2004). The three attentional networks: On their independence and interactions. Brain and Cognition, 54, 225-227.

Carter, C. S., Macdonald, A. M., Botvinick, M., Ross, L. L., Stenger, V. A., Noll, D., et al. (2000). Parsing executive processes: Strategic vs. evaluative functions of the anterior cingulate cortex. Proceedings of the National Academy of Sciences USA, 97, 1944-1948.

Cohen, J., Cohen, P., West, S. G., \& Aiken, L. S. (2003). Applied multiple regression/correlation analysis for the behavioral sciences (3rd ed.). Hillsdale, NJ: Erlbaum.

Cook, R. D. (1977). Detection of influential observations in linear regression. Technometrics, 19, 15-18.

Cropanzano, R., Goldman, B., \& Folger, R. (2003). Deontic justice: The role of moral principles in workplace fairness. Journal of Organizational Behavior, 24, 1019-1024.

De Cremer, D., \& Sedikides, C. (2005). Self-uncertainty and responsiveness to procedural justice. Journal of Experimental Social Psychology, $41,157-173$

De Cremer, D., \& Tyler, T. R. (2005). Managing group behavior: The interplay between procedural justice, sense of self, and cooperation. In M. P. Zanna (Ed.). Advances in experimental social psychology (Vol. 37, pp. 151-218). San Diego, CA: Academic Press.

De Waal, F. (1996). Good natured: The origins of right and wrong in humans and other animals. Cambridge, MA: Harvard University Press.

Eisenberger, N. I., Lieberman, M. D., \& Satpute, A. B. (in press). Personality from a controlled processing perspective: An fMRI study of neuroticism, extraversion, and self-consciousness. Cognitive, Affective, and Behavioral Neuroscience.

Eisenberger, N. I., \& Lieberman, M. D. (2004). Why rejection hurts: A common neural alarm system for physical and social pain. Trends in Cognitive Sciences, 8, 294-300.

Eisenberger, N. I., Lieberman, M. D., \& Williams, K. D. (2003). Does rejection hurt? An fMRI study of social exclusion. Science, 302, 290-292.

Elliot, A. J., Maier, M. A., Moller, A. C., Friedman, R., \& Meinhardt, J. (in press). Color and psychological functioning: The effect of red on performance attainment. Journal of Experimental Psychology: General.
Fazio, R. H. (1990). A practical guide to the use of response latency in social psychological research. In C. Hendrick \& M. S. Clark (Eds.), Research methods in personality and social psychology (pp. 74-97). Newbury Park, CA: Sage.

Folger, R. (Ed.). (1984). The sense of injustice: Social psychological perspectives. New York: Plenum.

Folger, R. (2001). Fairness as deonance. In S. Gilliland, D. Steiner, \& D. Skarlicki (Eds.), Theoretical and cultural perspectives on organizational justice (pp. 3-33). Greenwich, CT: Information Age Publishers.

Folger, R., \& Cropanzano, R. (1998). Organizational justice and human resource management. Thousand Oaks, CA: Sage.

Folger, R., Cropanzano, R., \& Goldman, B. (2005). What is the relationship between justice and morality?. In J. Greenberg \& J. A. Colquitt (Eds.) Handbook of organizational justice: Fundamental questions about fairness in the workplace (pp. 215-246). Mahwah, NJ: Erlbaum.

Folger, R., Rosenfield, D., Grove, J., \& Corkran, L. (1979). Effects of "voice" and peer opinions on responses to inequity. Journal of Personality and Social Psychology, 37, 2253-2261.

Folger, R., \& Skarlicki, D. P. (1998). A popcorn metaphor for employee aggression. In R. Griffin, A. O'Leary-Kelly, \& J. Collins (Eds.). Dysfunctional behavior in organizations: Violent behavior in organizations (Vol. 1, pp. 43-82). Greenwich, CT: JAI Press

Greenberg, J. (1993). Stealing in the name of justice: Informational and interpersonal moderators of theft reactions to underpayment inequity. Organizational Behavior and Human Decision Processes, 54, 81-103.

Greene, J. D., Nystrom, L. E., Engell, A. D., Darley, J. D., \& Cohen, J. D. (2004). The neural bases of cognitive conflict and control in moral judgment. Neuron, 44, 389-400.

Greene, J. D., Sommerville, B., Nystrom, L. E., Darley, J. M., \& Cohen, J. D. (2001). An fMRI investigation of emotional engagement in moral judgment. Science, 293, 2105-2108.

Hafer, C. L. (2000). Do innocent victims threaten the belief in a just world? Evidence from a modified Stroop task. Journal of Personality and Social Psychology, 79, 165-173.

Haidt, J. (2001). The emotional dog and its rational tail: A social intuitionist approach to moral judgment. Psychological Review, 108, 814-834.

Ham, J., \& Van den Bos, K. (submitted for publication). On the automaticity of justice knowledge activation.

Hays, W. L. (1981). Statistics (3rd ed.). New York: Holt-Saunders.

Hogg, M. A. (2004). Uncertainty and extremism: Identification with high entitativity groups under conditions of uncertainty. In V. Yzerbyt, C. M. Judd, \& O. Corneille (Eds.), The psychology of group perception: Perceived variability, entitativity, and essentialism (pp. 401-418). New York: Psychology Press.

Hogg, M. A. (2005). Uncertainty, social identity and ideology. In S. R. Thye \& E. J. Lawler (Eds.). Advances in group processes (Vol. 22, pp. 203-230). New York: Elsevier.

Kahneman, D., Knetsch, J. L., \& Thaler, R. H. (1986). Fairness and the assumptions of economics. Journal of Business, 59, 285-300.

Kirk, R. E. (1995). Experimental design: Procedures for the behavioral sciences (3rd ed.). Pacific Grove, CA: Brooks/Cole.

Klein, D. F. (1996). Panic disorder and agoraphobia: Hypothesis hothouse. Journal of Clinical Psychiatry, 57, 21-27.

Lang, P. J., Greenwald, M. K., Bradley, M. M., \& Hamm, A. O. (1993). Looking at pictures: Affective, facial, visceral, and behavioral reactions. Psychophysiology, 30, 261-273.

Lerner, M. J. (1977). The justice motive: Some hypotheses as to its origins and forms. Journal of Personality, 45, 1-52.

Lerner, M. J. (1980). The belief in a just world: A fundamental delusion. New York: Plenum Press.

Lerner, M. J. (2003). The justice motive: Where social psychologists found it, how they lost it, and why they may not find it again. Personality and Social Psychology Review, 7, 388-399.

Leung, K., Tong, K.-K., \& Ho, S. S.-H. (2004). Effects of interactional justice on egocentric bias in resource allocation decisions. Journal of Applied Psychology, 89, 405-415. 
Leventhal, G. S. (1980). What should be done with equity theory? New approaches to the study of fairness in social relationships. In K. J. Gergen, M. S. Greenberg, \& R. H. Willis (Eds.), Social exchange: Advances in theory and research (pp. 27-54). New York: Plenum.

Liddell, B. J., Brown, K. J., Kemp, A. H., Barton, M. J., Das, P., Peduto, A., et al. (2005). A direct brainstem-amygdala-cortical 'alarm' system for subliminal signals of fear. Neuroimage, 24, 235-243.

Lieberman, M. D. (2003). Reflexive and reflective judgment processes: A social cognitive neuroscience approach. In J. P. Forgas, K. P. Williams, \& W. Von Hippel (Eds.), Social judgments: Implicit and explicit processes (pp. 44-67). Cambridge, UK: Cambridge University Press.

Lieberman, M. D., \& Eisenberger, N. I. (2004). The neural alarm system: Behavior and beyond. Reply to Ullsperger et al.. Trends in Cognitive Sciences, 8, 446-447.

Lieberman, M. D., Gaunt, R., Gilbert, D. T., \& Trope, Y. (2002). Reflexion and reflection: A social cognitive neuroscience approach to attributional inference. In M. P. Zanna (Ed.). Advances in experimental social psychology (Vol. 34, pp. 199-249). San Diego, CA: Academic Press.

Lind, E. A. (2001). Fairness heuristic theory: Justice judgments as pivotal cognitions in organizational relations. In J. Greenberg \& R. Cropanzano (Eds.), Advances in organizational behavior (pp. 56-88). Stanford, CA: Stanford University Press.

Lind, E. A., Greenberg, J., Scott, K. S., \& Welchans, T. D. (2000). The winding road from employee to complainant: Situational and psychological determinants of wrongful termination claims. Administrative Science Quarterly, 45, 557-590.

Lind, E. A., Kanfer, R., \& Earley, P. C. (1990). Voice, control, and procedural justice: Instrumental and noninstrumental concerns in fairness judgments. Journal of Personality and Social Psychology, 59, 952-959.

Lind, E. A., \& Tyler, T. R. (1988). The social psychology of procedural justice. New York: Plenum.

Loseman, A., Van den Bos, K., \& Ham, J. (2006). The social psychology of justice as a self-related process. Paper presented at the Eleventh International Conference on Social Justice Research, Berlin, Germany.

Maas, M., \& Van den Bos, K. (submitted for publication). An affectiveexperiential perspective on reactions to fair and unfair events: Effects of individual differences in affect intensity moderated by experiential mindsets.

McGregor, I. (2004). Zeal, identity, and meaning: Going to extremes to be one self. In J. Greenberg, S. L. Koole, \& T. Pyszczynski (Eds.), Handbook of experimental existential psychology (pp. 182-199). New York: Guilford Press.

McGregor, I., Zanna, M. P., Holmes, J. G., \& Spencer, S. J. (2001). Compensatory conviction in the face of personal uncertainty: Going to extremes and being oneself. Journal of Personality and Social Psychology, 80, 472-488.

Miedema, J., Van den Bos, K., \& Vermunt, R. (2006). The influence of self-threats on fairness judgments and affective measures. Social Justice Research, 19, 228-253.

Mikula, G. (2005). Some observations and critical thoughts about the present state of justice theory and research. In S. Gilliland, D. Steiner, D. Skarlicki, \& K. van den Bos (Eds.), What motivates fairness in organizations (pp. 197-210). Greenwich, CT: Information Age Publishing.

Montada, L. (1998). Justice: Just a rational choice?. Social Justice Research 12, 81-101.

Montada, L. (2002). Doing justice to the justice motive. In M. Ross \& D. T. Miller (Eds.), The justice motive in everyday life (pp. 41-62). Cambridge, UK: Cambridge University Press.

Moorman, R. H., \& Byrne, Z. S. (2005). How does organizational justice affect organizational citizenship behavior? In J. Greenberg \& J. A. Colquitt (Eds.), Handbook of organizational justice: Fundamental questions about fairness in the workplace (pp. 355-380). Mahwah, NJ: Erlbaum.
Murray, S. L. (2005). Regulating the risks of closeness: A relationshipspecific sense of felt security. Current Directions in Psychological Science, 14, 74-78.

Murray, S. L., Holmes, J. G., \& Collins, N. L. (2005). The relational signature of felt security. Paper presented at the 2005 Conference of the Society of Experimental Social Psychology, San Diego, USA.

Murray, S. L., Holmes, J. G., \& Griffin, D. W. (2000). Self-esteem and the quest for felt security: How perceived regard regulates attachment processes. Journal of Personality and Social Psychology, 78, 478-498.

Murray, S. L., Holmes, J. G., MacDonald, G., \& Ellsworth, P. C. (1998). Through the looking glass darkly? When self-doubts turn into relationship insecurities. Journal of Personality and Social Psychology, $75,1459-1480$.

Murray, S. L., Rose, P., Bellavia, G. M., Holmes, J. G., \& Garrett Kusche, A. (2002). When rejection stings: How self-esteem constrains relationship-enhancement processes. Journal of Personality and Social Psychology, 83, 556-573.

Posner, M. I., \& Petersen, S. E. (1990). The attention system of the human brain. Annual Review of Neuroscience, 13, 25-42.

Steiner, D. D., Guirard, S., \& Baccino, T. (1999, May). Cognitive processing of procedural justice information: Application of the Oculometer. Paper presented at the Annual Conference of the Society for Industrial/Organizational Psychology, Atlanta, GA.

Strack, F., \& Deutsch, R. (2004). Reflective and impulsive determinants of social behavior. Personality and Social Psychology Review, 8, 220-247.

Tabachnick, B. G., \& Fidell, L. S. (1989). Using multivariate statistics (2nd ed.). New York: Harper \& Row.

Thibaut, J., \& Kelley, H. H. (1959). The social psychology of groups. New York: Wiley.

Tillfors, M. (2004). Why do some individuals develop social phobia? A review with emphasis on the neurobiological influences. Nordic Journal of Psychiatry, 58, 267-276.

Tyler, T. R. (2006). Why people obey the law. Princeton, NJ: Princeton University Press.

Tyler, T. R., \& Lind, E. A. (1992). A relational model of authority in groups. In M. P. Zanna (Ed.). Advances in experimental social psychology (Vol. 25, pp. 115-191). San Diego, CA: Academic Press.

Van den Bos, K. (2001). Uncertainty management: The influence of uncertainty salience on reactions to perceived procedural fairness. Journal of Personality and Social Psychology, 80, 931-941.

Van den Bos, K. (in press). Hot cognition and social justice judgments: The combined influence of cognitive and affective factors on the justice judgment process. In D. de Cremer (Ed.), Advances in the psychology of justice and affect. Greenwich, CT: Information Age Publishing.

Van den Bos, K., \& Rijpkema, M. (2007). Studying effects of exclamation point primes using functional neuroimaging. Unpublished manuscript.

Van den Bos, K., Miedema, J., \& Vermunt, R. (submitted for publication). Exploring how people respond to conflicts between self-interest and fairness: The influence of threats to the self on reactions to advantageous inequity.

Van den Bos, K., Heuven, E., Burger, E., \& Fernández Van Veldhuizen, M. (2006). Uncertainty management after reorganizations: The ameliorative effect of outcome fairness on job uncertainty. International Review of Social Psychology, 19, 75-86.

Van den Bos, K., \& Lind, E. A. (2002). Uncertainty management by means of fairness judgments. In M. P. Zanna (Ed.). Advances in experimental social psychology (Vol. 34, pp. 1-60). San Diego, CA: Academic Press.

Van den Bos, K., Lind, E. A., \& Wilke, H. A. M. (2001). The psychology of procedural and distributive justice viewed from the perspective of fairness heuristic theory. In R. Cropanzano (Ed.), Justice in the workplace: Volume 2 - From theory to practice (pp. 49-66). Mahwah, NJ: Erlbaum.

Van den Bos, K., Lind, E. A., Vermunt, R., \& Wilke, H. A. M. (1997). How do I judge my outcome when I do not know the outcome of others? The psychology of the fair process effect. Journal of Personality and Social Psychology, 72, 1034-1046. 
Van den Bos, K., \& Miedema, J. (2000). Toward understanding why fairness matters: The influence of mortality salience on reactions to procedural fairness. Journal of Personality and Social Psychology, 79, 355-366.

Van den Bos, K., Poortvliet, P. M., Maas, M., Miedema, J., \& Van den Ham, E.-J. (2005). An enquiry concerning the principles of cultural norms and values: The impact of uncertainty and mortality salience on reactions to violations and bolstering of cultural worldviews. Journal of Experimental Social Psychology, 41, 91-113.

Van den Bos, K., \& Van Prooijen, J.-W. (2001). Referent cognitions theory: The role of closeness of reference points in the psychology of voice. Journal of Personality and Social Psychology, 81, 616-626.

Van den Bos, K., Vermunt, R., \& Wilke, H. A. M. (1997). Procedural and distributive justice: What is fair depends more on what comes first than on what comes next. Journal of Personality and Social Psychology, 72, 95-104.

Van den Bos, K., Wilke, H. A. M., Lind, E. A., \& Vermunt, R. (1998). Evaluating outcomes by means of the fair process effect: Evidence for different processes in fairness and satisfaction judgments. Journal of Personality and Social Psychology, 74, 1493-1503.

Van Prooijen, J.-W., Karremans, J. C., \& Van Beest, I. (2006). Procedural justice and the hedonic principle: How approach versus avoidance motivation influences the psychology of voice. Journal of Personality and Social Psychology, 91, 686-697.

Watson, D., Clark, L. A., \& Tellegen, A. (1988). Development and validation of brief measures of positive and negative affect: The PANAS scales. Journal of Personality and Social Psychology, 54, 1063-1070. 